Published in final form as:

Liedel, C., \& Ober, C. K. (2016). Nanopatterning of Stable Radical Containing Block Copolymers for Highly Ordered Functional Nanomeshes.

Macromolecules, 49(16), 5884-5892. doi:10.1021/acs.macromol.6b00392

\title{
Nanopatterning of Stable Radical Containing Block Copolymers for Highly Ordered
} Functional Nanomeshes

Clemens Liedel, Christopher K. Ober

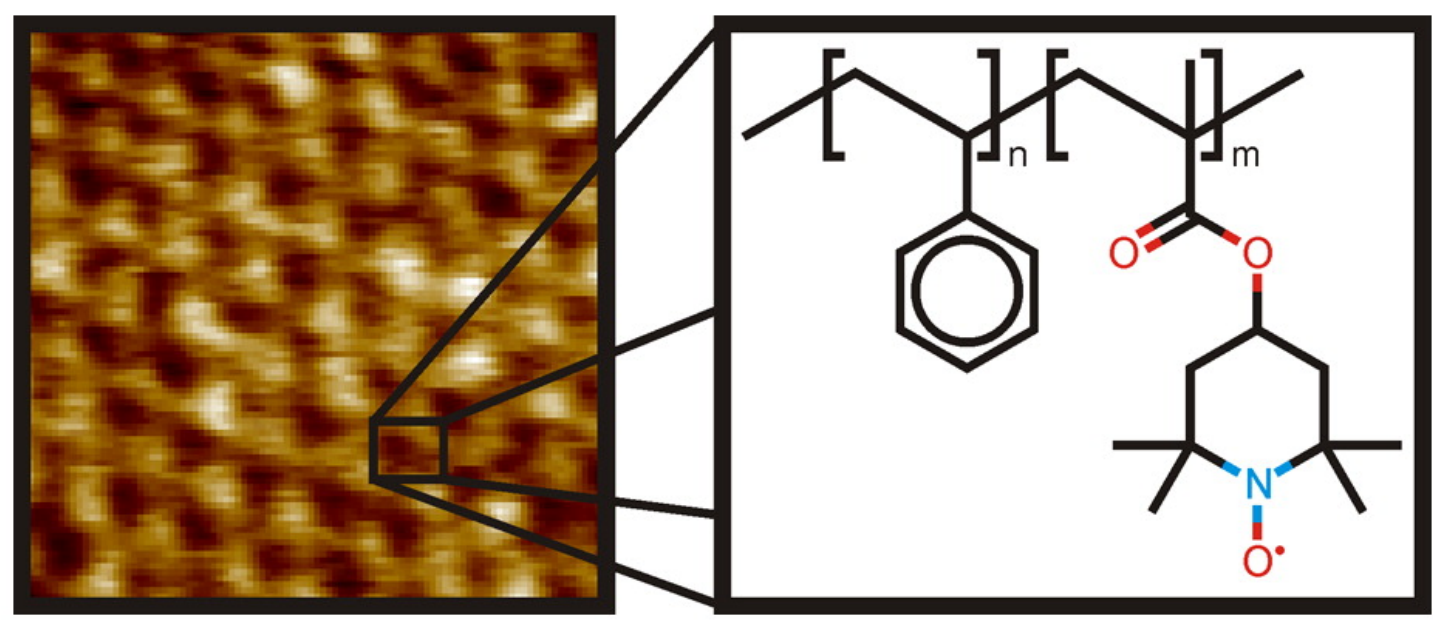




\title{
Nanopatterning of Stable Radical Containing Block Copolymers for Highly Ordered Functional
}

\section{Nanomeshes}

\author{
Clemens Liedel, ${ }^{\dagger, *}$ Christopher K. Ober, \\ $\dagger$ Department of Colloid Chemistry, Max Planck Institute of Colloids and Interfaces, Research \\ Campus Golm, 14476 Potsdam, Germany \\ \$ Materials Science and Engineering, 214 Bard Hall, Cornell University, Ithaca, NY 14853, USA
}

ABSTRACT: We present a method for patterning substrates with a regular mesh of stable radical groups. Resulting from advanced block copolymer synthesis and annealing techniques, stable radical groups on a polymer backbone phase separate from the second block and arrange in ordered block copolymer morphologies. These meshes align in large regular patterns upon sample preparation on macroscopically structured substrates. Patterned stable radical groups may find application in selective catalysis, energy storage, data storage or optical gratings. In addition gas permeable membranes with reactive sites or charge storage zones with regular spacings in redox batteries may be feasible by our approach. 


\section{INTRODUCTION}

Stable organic radical containing molecules are finding use in organic synthesis, ${ }^{1}$ but also in controlled polymerization techniques ${ }^{2}$ and in biological applications. ${ }^{3}$ The most prominent stable radical organic compounds involve (2,2,6,6-tetramethylpiperidin-1-yl)oxyl (TEMPO) which features a sterically protected nitroxide group.

In general, dense patterning of reactive groups on a surface at small length scales is a promising method for optoelectronic, biological or information storage applications. ${ }^{4-6}$ Confined nitroxide radicals on a regular arrangement could be used in data storage or spatially restricted chemical transformations. $^{7,8}$

By binding stable nitroxide radical groups to polymer backbones, Nakahara et al. have developed polymeric electrode materials for battery applications. ${ }^{9}$ Charge storage was enabled by the fast and reversible one-electron transfer reaction of the nitroxide radical species to the oxammonium cation or the aminoxy anion. Following this approach, different groups of researchers have investigated polymers with a multitude of stable radical groups for battery applications and advanced polymerization methods. ${ }^{10-12}$ The most thoroughly investigated polymer with stable radical groups is poly(2,2,6,6-tetramethylpiperidinyloxy-4-yl methacrylate (PTMA).

In order to combine the redox activity of such polymers with other material properties, new copolymers were developed. ${ }^{13}$ Block copolymers with a stable radical block and another functional block could, in the case of long-range ordered self-assembly, lead to patterned 
nitroxide groups on a surface. Self-assembly of block copolymers, however, is hindered if polymer chain length is ill-defined or shorter than a composition and interaction parameter dependent value. Additionally, polymer films after film preparation are often not in equilibrium. Hence, early reports on block copolymers with a stable radical containing block did not clearly show phase separated block copolymer structures like lamellae, cylinders or hexagonally packed spheres. ${ }^{7,14-17}$ Only recently, we ${ }^{18}$ and others ${ }^{19,20}$ have investigated phase separation in PTMA containing block copolymers and described the necessity of advanced annealing techniques, a low dispersity and a large $\chi \mathrm{N}$ value (product of the Flory Huggins interaction parameter and the degree of polymerization, DP).

The block copolymer films we presented previously featured upright-standing cylinders with negligible grain size among ordered domains. ${ }^{18}$ Similarly, other phase-separated block copolymer films as presented by Boudouris et al. exhibited no clear order. ${ }^{19}$ Gohy and coworkers have reported block copolymer films which were ordered in grains of approx. $150 \mathrm{~nm}$ diameter after solvent vapor annealing. ${ }^{20}$ The nature of the solvent mixture directed the preferential orientation of the cylinders. Still, no long-range order above a few hundred nm was provided. Thermal annealing led to no clearly phase separated structures at all. All these examples had in common the use of controlled radical polymerization methods, which usually led to dispersities in the range of 1.2, larger than expected in anionic polymerization. Another disadvantage of controlled radical polymerization techniques is that usually only approx. $70 \%$ of monomeric repeating units in the PTMA block contain radical groups. ${ }^{21}$

Anionic polymerization of PTMA, which is promising to make block copolymers with a lower dispersity than controlled radical polymerization and hence better ordered structures, was first demonstrated by Griffith and coworkers. ${ }^{22}$ In contrast to controlled radical polymerization 
techniques, no functionalization of precursor polymers is necessary, resulting in a quantitative yield of radical groups in the polymer. ${ }^{23-25}$ Still, PTMA containing block copolymers by carbanionic polymerization have not yet been described to the best of our knowledge.

In general, self-assembly of block copolymers during advanced annealing techniques leads to ordered patterns in grains, which usually are several hundred nanometers in diameter. ${ }^{26}$ Alignment techniques like external fields or patterned surfaces are promising for creation of long-range ordered structures in the micrometer range or above. ${ }^{27}$

Alignment of block copolymers with stable radical groups may lead to long-range ordered functionally patterned surfaces but has not been investigated to date. In this publication, we will demonstrate a combination of advanced synthesis, annealing and alignment techniques to yield such long-range ordered patterns of stable radical groups. The choice of the second block, which does not contain stable radicals, is important. For combining different material properties, several choices are imaginable. Nishide et al. used a polyelectrolyte second block to increase ion conductivity. ${ }^{7}$ Gohy et al. focused on block copolymers based on PTMA and polystyrene since the polystyrene could be crosslinked. ${ }^{15,17,20}$ In this contribution, we use both approaches: we describe the anionic polymerization and structure formation of PTMA containing block copolymers with polystyrene or with tert-butyl methacrylate as a second block. The latter could easily be hydrolyzed to polyacrylic acid, a common polyelectrolyte.

\section{EXPERIMENTAL SECTION}


We have synthesized PTMA based block copolymers with tert-butyl methacrylate or styrene second blocks (poly(tert-butyl methacrylate)-block-poly(2,2,6,6-tetramethylpiperidinyloxy-4-yl methacrylate), PtBMA-b-PTMA and polystyrene-block-poly(2,2,6,6-tetramethylpiperidinyloxy4-yl methacrylate), PS- $b$-PTMA, respectively). Following a modification of the approach by Nishide and coworkers, we used methacrylate capped macroinitiators for the anionic polymerization of the PTMA block. ${ }^{24}$ Scheme 1 shows structures of these polymers.

Scheme 1. Structures of PtBMA- $b$-PTMA (1) and PS- $b$-PTMA (2) block copolymers.

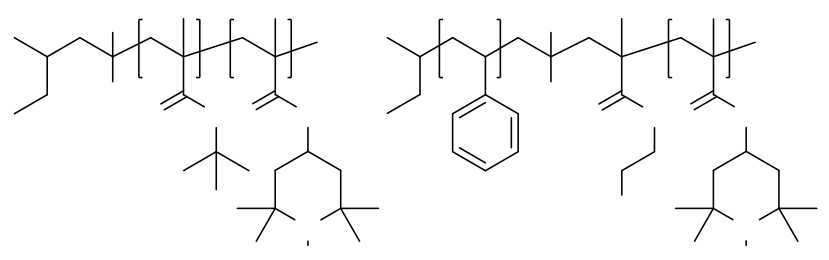

Monomer and Solvent Purification. The stable radical containing monomer, 2,2,6,6tetramethylpiperidinyloxy-4-yl methacrylate (TMA) was synthesized according to reference ${ }^{28}$, purified by extraction, column chromatography and recrystallization, dried in vacuum for several days and transferred into a glove box with nitrogen atmosphere. tert-Butyl methacrylate ( $t \mathrm{BMA})$, styrene, trimethylsilyl protected 2-hydroxyethyl methacrylate (TMS-HEMA) and diphenylethylene (DPE) were obtained commercially, stirred over calcium hydride for several days and distilled under reduced pressure at slightly elevated temperature. Tetrahydrofuran (THF) and toluene were stirred over calcium hydride for several days and distilled into flasks equipped with sodium and benzophenone. Subsequently, the solvents were distilled into other flasks at reduced pressure. All liquids were degassed by several freeze-pump-thaw cycles and transferred into a nitrogen filled glove box. 
Synthesis of PtBMA- $b$-PTMA Block Copolymers. The synthesis of $\mathrm{P} \mathrm{BMA}_{104}-b-\mathrm{PTMA}_{34}$ is described as an example. Other P $t$ BMA- $b$-PTMA polymers were synthesized accordingly. In a nitrogen filled glove box, a dry flask with a Rotaflo ${ }^{\circledR}$ stopcock was equipped with $7.5 \mathrm{mg} \mathrm{LiCl}$ (0.18 mmol, dried in vacuum) and $67.5 \mathrm{~mL}$ THF. The flask was additionally sealed with a septum and transferred to a THF/dry ice bath. The atmosphere was exchanged to argon. Approx. $150 \mu \mathrm{L}$ of a sec-butyl lithium solution (1.4 M in cyclohexane) were added with a degassed needle. The flask was allowed to slowly warm up in order to let the sec-butyl lithium react with impurities and then with THF. After cooling to $-78^{\circ} \mathrm{C}, 24 \mu \mathrm{L}$ DPE $(0.14 \mathrm{mmol})$ were added with a degassed syringe. No color change was observed, indicating complete deactivation of the previously added butyl lithium. $32 \mu \mathrm{L}$ sec-butyl lithium solution $(0.045 \mathrm{mmol})$ were added with a degassed syringe. The reaction mixture turned red. After stirring for $30 \mathrm{~min}, 5.3 \mathrm{~mL} t \mathrm{BMA}$ (32.6 mmol) were added with a degassed syringe. The solution immediately turned colorless. After $24 \mathrm{~h}$ reaction, a small sample was taken for analysis of the first block. The reaction mixture was transferred to a cooling bath at $-61^{\circ} \mathrm{C}$ followed by addition of $7.5 \mathrm{~mL}$ of a TMA solution (0.2 $\mathrm{g} \mathrm{mL}^{-1}$ in toluene; $6.2 \mathrm{mmol}$ TMA), resulting in a toluene:THF ratio of 1:9 (v:v). After $4.5 \mathrm{~h}$, the reaction was quenched by adding $5 \mathrm{~mL}$ degassed methanol. After warming up to room temperature, the pale red polymer was precipitated twice into $50 \%$ methanol in water and dried in vacuum at $50{ }^{\circ} \mathrm{C}$ over night.

Synthesis of PS- $b$-PTMA Block Copolymers. The synthesis of $\mathrm{PS}_{45}-b$-PTMA 45 is described as an example. Other PS- $b$-PTMA polymers were synthesized accordingly. In a nitrogen filled glove box, a dry flask with a Rotaflo $^{\circledR}$ stopcock was equipped with $9.6 \mathrm{mg} \mathrm{LiCl} \mathrm{(0.23} \mathrm{mmol,}$ dried in vacuum) and $45 \mathrm{~mL}$ THF. The flask was additionally sealed with a septum and transferred to a THF/dry ice bath. The atmosphere was exchanged to argon. Approx. $150 \mu \mathrm{L}$ of a 
sec-butyl lithium solution (1.4 M in cyclohexane) were added with a degassed needle. The flask was slowly allowed to warm up in order to let the sec-butyl lithium react with impurities and then with THF. After cooling to $-78{ }^{\circ} \mathrm{C}$, first $16 \mu \mathrm{L}$ sec-butyl lithium solution $(0.023 \mathrm{mmol})$, followed by $1.1 \mathrm{~mL}$ styrene $(9.60 \mathrm{mmol})$ were added with a degassed syringe. The reaction immediately turned yellow. After $30 \mathrm{~min}, 16 \mu \mathrm{L}$ DPE $(0.09 \mathrm{mmol})$ were added with a degassed syringe, and the reaction turned red. After $60 \mathrm{~min}$, a sample was taken for analysis. One drop of TMS-HEMA was added with a degassed syringe, and the reaction turned clear. After transfer to a cooling bath at $-61^{\circ} \mathrm{C}, 5.0 \mathrm{~mL}$ of a TMA solution $\left(0.2 \mathrm{~g} \mathrm{~mL}^{-1}\right.$ in toluene; $4.2 \mathrm{mmol}$ TMA), resulting in a toluene:THF ratio of 1:9 (v:v), were added with a degassed syringe. The reaction was quenched by adding $1 \mathrm{~mL}$ degassed methanol after $22 \mathrm{~h}$. The crude product was precipitated twice into $50 \%$ methanol in water after warming to room temperature. The pale red polymer was dried in vacuum at $55^{\circ} \mathrm{C}$ over night.

Swelling Experiments in Chloroform and Toluene Vapor. After spin-coating from solutions in chloroform (20 mg mL $\left.{ }^{-1}\right)$, PS and PTMA homopolymer films of comparable thickness and molecular weight were placed in a stainless steel chamber equipped with gas inlet and outlet, solvent inlet and a Filmetrics F20 refractometer to measure the film thickness in-situ during solvent vapor annealing. After determining the dry film thickness, $5 \mathrm{~mL}$ of the respective solvent were introduced to the chamber while nitrogen was flowing through it at a constant flow rate. This prevented the films from dewetting due to swelling to a very high degree. The gas flow was kept constant for all measurements to yield comparable conditions. The film thickness was continuously measured and plotted; the degree of swelling was calculated from the maximally swollen film thickness and the initial film thickness. 
Film Formation and Annealing. Polymer solutions in chloroform or toluene were filtered and spin-coated onto cleaned silicon wafers $\left(\sim 1 \mathrm{~cm}^{2}\right.$, stored in toluene, cleaned with acetone, isopropanol and plasma treatment immediately before use). The film thickness of the dry films (dried at ambient conditions for a prolonged time) was measured with a Filmetrics F20 refractometer. Samples were thermally annealed on a pre-heated hot plate or in solvent atmosphere by placing them into a glass chamber with small opening to facilitate pressure equalization and slow drying of the films after chloroform annealing by slow evaporation of the solvent.

Polymer Analysis. Infrared spectroscopy (IR) was measured using a Thermo Scientific Nicolet iS5 FT-IR spectrometer. For measuring proton nuclear magnetic resonance $\left({ }^{1} \mathrm{H}-\mathrm{NMR}\right)$ spectra, the polymers were dissolved in $\mathrm{CDCl}_{3}$, a fresh solution of phenylhydrazine $(0.03 \mathrm{M}$ in $\mathrm{CDCl}_{3} ; 0.65$ eq with respect to the calculated number of stable radical groups) was added, and the spectra were measured using an Agilent $400 \mathrm{MHz}$ NMR within 10 min after mixing (after the reddish color had disappeared). Cyclic voltammetry (CV) was measured using a BioLogic MPG2 potentiostat, glassy carbon working electrode, platinum wire counter electrode and $\mathrm{Ag} / \mathrm{AgNO}_{3}$ reference electrode with Tetrabutylammonium hexafluorophosphate as auxiliary electrolyte. ${ }^{20}$ Gel Permeation Chromatography (GPC) was measured using a Waters AmbientTemperature GPC in THF with a Waters $486 \mathrm{UV}-\mathrm{Vis}$ detector, calibrated with polystyrene standard. Thermal behavior of the polymers was determined using a TA Instruments Q500 Thermogravimetric Analyzer (TGA) and a TA Instruments Q1000 Modulated Differential Scanning Calorimeter (DSC). Atomic Force Microscopy (AFM) images were taken at a Veeco Icon AFM with Olympus AC160TS probes. 


\section{RESULTS AND DISCUSSION}

PtBMA-b-PTMA. Selected P $t$ BMA- $b$-PTMA block copolymers were synthesized by anionic polymerization from tert-butyl methacrylate and the radical containing monomer without the need of protecting and deprotecting the radical functionality before and after polymerization, respectively (Scheme 2). Since the TMA monomer contained stable radical groups, no postpolymerization functionalization is necessary. The order of polymerization was chosen so a methacrylate containing macroinitiator could be used for the PTMA polymerization, as suggested in the literature. ${ }^{24}$

sec-Butyl lithium reactivity was decreased upon reaction with DPE. The polymerization of $t$ BMA was carried out at $-78^{\circ} \mathrm{C}$ in dry THF. Introduction of a solution of TMA in dry toluene at $-61{ }^{\circ} \mathrm{C}$ yielded block copolymers of the desired composition. Table 1 summarizes properties of these polymers. More PtBMA- $b$-PTMA block copolymers are described in the supporting information. A PTMA quasi-homopolymer resulted for negligible amounts of tert-butyl methacrylate.

Scheme 2. Pathway to synthesize P $t$ BMA- $b$-PTMA block copolymers.
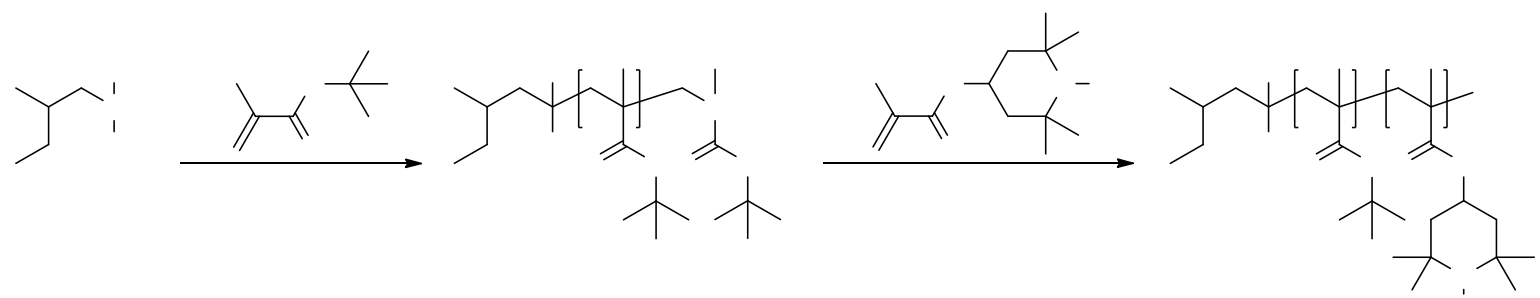

Table 1. PtBMA- $b$-PTMA block copolymers. 


\begin{tabular}{|c|c|c|c|c|c|c|c|c|c|c|c|c|}
\hline \multirow[t]{3}{*}{ sample } & \multicolumn{4}{|c|}{ PtBMA block } & \multicolumn{4}{|c|}{ PTMA block } & \multicolumn{4}{|c|}{ PtBMA-b-PTMA block copolymer } \\
\hline & \multicolumn{2}{|c|}{ calculated $^{\dagger}$} & \multicolumn{2}{|c|}{ measured $(\mathrm{GPC})^{*}$} & \multicolumn{2}{|c|}{ calculated $^{\dagger}$} & \multicolumn{2}{|c|}{ measured (GPC) } & \multirow{2}{*}{$\begin{array}{c}\text { yield } \\
/ \%\end{array}$} & \multirow{2}{*}{$\begin{array}{c}\mathbf{M}_{\mathrm{n}, \mathrm{th}^{\dagger}}^{\dagger} \\
/ \mathbf{k g ~ m o l}^{-1}\end{array}$} & \multirow{2}{*}{$\begin{array}{c}\mathrm{M}_{\mathrm{n}, \mathrm{GPC}} \\
/ \mathrm{kg} \mathrm{mol}^{-1}\end{array}$} & \multirow{2}{*}{$\begin{array}{c}M_{w} / M_{n} \\
(G P C)\end{array}$} \\
\hline & DP & $\mathrm{M}_{\mathrm{n}} / \mathrm{kg} \mathrm{mol}^{-1}$ & DP & $\mathrm{M}_{\mathrm{n}} / \mathrm{kg} \mathrm{mol}^{-1}$ & DP & $\mathrm{M}_{\mathrm{n}} / \mathrm{kg} \mathrm{mol}^{-1}$ & DP & $M_{n} / \mathrm{kg} \mathrm{mol}^{-1}$ & & & & \\
\hline PTMA $_{20}$ & - & - & - & - & 84 & 20.1 & 54 & 13.5 & 77.1 & 20.1 & 13.5 & 1.04 \\
\hline $\operatorname{P}_{t \mathrm{BMA}_{52}-b-\mathrm{PTMA}}$ & 364 & 51.8 & 362 & 51.5 & 70 & 16.7 & 71 & 17.1 & 98.1 & 68.5 & 68.5 & 1.08 \\
\hline 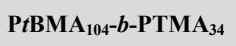 & 728 & 103.5 & 759 & 107.9 & 139 & 33.5 & 228 & 54.8 & 96.4 & 137.0 & 162.7 & 1.13 \\
\hline
\end{tabular}

The polymers in Table 1 feature a low dispersity and long block lengths of asymmetric polymers with PTMA being the minority component. The low dispersity and high molecular weight indicate high purity of the monomers: if some of the monomers contained secondary amines instead of stable radical groups, the growing chains would be quenched by abstraction of protons. Such termination reactions would lead to short and ill-defined polymers. The dispersity and degree of polymerization are expected to support ordered structure formation, and the highly asymmetric composition makes the spherical or cylindrical morphology the most probable structure.

Additionally to the GPC measurements, we analyzed the resulting P $t$ BMA- $b$-PTMA polymers by IR and NMR spectroscopy and cyclic voltammetry. IR spectroscopy (Figure SI-1 in the Supporting Information) clearly shows the existence of nitroxide groups in the final polymers $\left(\mathrm{N}-\mathrm{O} \cdot\right.$ peak at $\left.1367 \mathrm{~cm}^{-1}\right) \cdot{ }^{29,30}$ Because of similar block ratios, spectra (both concerning peak occurrence and intensities) are almost identical. NMR measurements of the polymers after reduction with phenlyhydrazine (Figure SI-2 in the Supporting Information) also shows the absence of impurities and successful polymerization due to peaks from both the PtBMA $\left(\mathrm{OC}\left(\underline{\mathrm{CH}}_{3}\right)_{3}\right.$ at $\left.1.33 \mathrm{ppm}\right)$ and PTMA $\left(\mathrm{OCH}\left(\mathrm{CH}_{2}\right)_{2}\right.$ at $\left.4.82 \mathrm{ppm}\right)$ homopolymer blocks. ${ }^{31} \mathrm{Cyclic}$ voltammetry (Figure SI-3 in the Supporting Information) shows the redox peak at $0.465 \mathrm{~V}$ vs. $\mathrm{Ag} / \mathrm{AgNO}_{3}{ }^{20}$ 
GPC evaluation of the block lengths differs slightly from the estimated composition (assuming $100 \%$ conversion). However, taking into account the yield of only $77.1 \%$ for the PTMA quasihomopolymer due to a shorter polymerization time, only the composition of P $t$ BMA- $b$-PTMA10 is slightly off, probably caused by a less accurate GPC calibration in the high $\mathrm{M}_{\mathrm{n}}$ range and the calibration with polystyrene samples. TGA and DSC data in the Supporting Information (Figure SI-4) confirms polymer stability. Polymers do not decompose (but might undergo crosslinking reactions, vide infra) up to approximately $220^{\circ} \mathrm{C}$. Glass transition temperatures of the PTMA homopolymer and the block copolymers are around $150{ }^{\circ} \mathrm{C}$ and $120^{\circ} \mathrm{C}$, respectively.

PS-b-PTMA. For making PS- $b$-PTMA, we first synthesized polystyrene in dry THF at $-78^{\circ} \mathrm{C}$ using sec-butyl lithium as initiator and end-capped this macroinitiator with diphenylethylene. Polymerization of this block first is crucial as a growing methacrylate chain anion would not be reactive enough to initiate polystyrene polymerization. Since the resulting polymeric anion is prone to a one electron transfer reaction to the TMA monomer, ${ }^{24}$ introduction of a short unit of another methacrylate is necessary before polymerizing the radical containing monomer. Scheme 3 shows the reaction conditions, and Table 2 summarizes the compositions of the resulting polymers. Since we directly polymerized radical containing monomers, no postpolymerization functionalization was necessary.

Scheme 3. Pathway to synthesize PS- $b$-PTMA block copolymers.
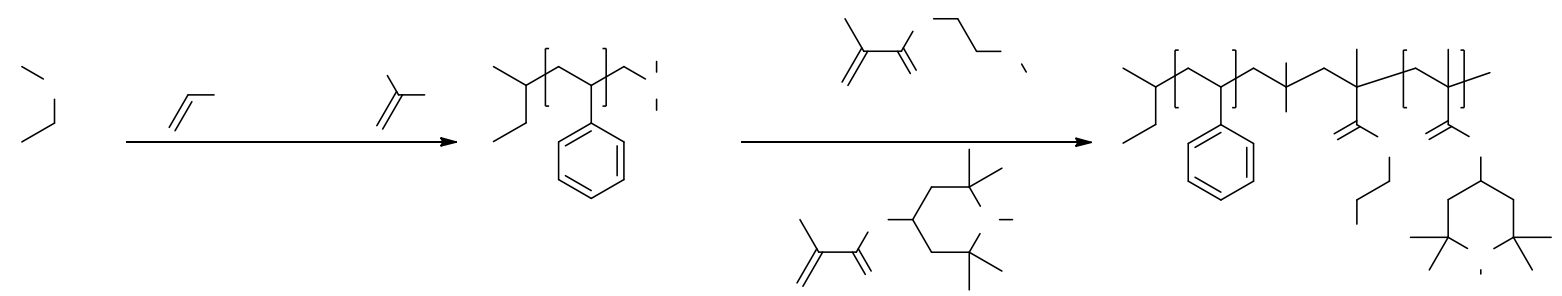
Table 2. PS- $b$-PTMA block copolymers.

\begin{tabular}{|c|c|c|c|c|c|c|c|c|c|c|c|c|}
\hline \multirow[t]{3}{*}{ sample } & \multicolumn{4}{|c|}{ PS block } & \multicolumn{4}{|c|}{ PTMA block } & \multicolumn{4}{|c|}{ PS-b-PTMA block copolymer } \\
\hline & \multicolumn{2}{|c|}{ calculated $^{\dagger}$} & \multicolumn{2}{|c|}{ measured (GPC) } & \multicolumn{2}{|c|}{ calculated $^{\dagger}$} & \multicolumn{2}{|c|}{ measured (GPC) $)^{\ddagger}$} & \multirow{2}{*}{$\begin{array}{c}\text { yield } \\
/ \%\end{array}$} & \multirow{2}{*}{$\begin{array}{c}\mathbf{M}_{\mathrm{n}, \mathrm{th}^{\dagger}} \\
/ \mathrm{kg} \mathrm{mol}^{-1}\end{array}$} & \multirow{2}{*}{$\begin{array}{c}\mathrm{M}_{\mathrm{n}, \mathrm{GPC}^{*}} \\
/ \mathrm{kg} \mathrm{mol}^{-1}\end{array}$} & \multirow{2}{*}{$\begin{array}{c}\mathbf{M}_{\mathrm{w}} / \mathbf{M}_{\mathrm{n}} \\
(\mathrm{GPC})\end{array}$} \\
\hline & DP & $\mathrm{M}_{\mathrm{n}} / \mathrm{kg} \mathrm{mol}^{-1}$ & DP & $\mathrm{M}_{\mathrm{n}} / \mathrm{kg} \mathrm{mol}^{-1}$ & DP & $\mathrm{M}_{\mathrm{n}} / \mathrm{kg} \mathrm{mol}^{-1}$ & DP & $\mathrm{M}_{\mathrm{n}} / \mathrm{kg} \mathrm{mol}^{-1}$ & & & & \\
\hline PS $_{35}-b$-PTMA $A_{22}$ & 243 & 34.5 & 228 & 32.4 & 93 & 22.3 & 47 & 11.2 & 97.2 & 56.8 & 43.6 & 1.08 \\
\hline $\mathrm{PS}_{69}-b-\mathrm{PTMA} 45$ & 485 & 69.0 & 483 & 68.7 & 186 & 44.6 & 92 & 22.0 & 98.6 & 113.6 & 90.8 & 1.04 \\
\hline $\mathrm{PS}_{45}-b-\mathrm{PTMA} 45$ & 314 & 44.6 & 310 & 44.1 & 186 & 44.6 & 90 & 21.6 & 94.2 & 89.3 & 65.6 & 1.05 \\
\hline PS $_{15}-b$-PTMA 45 & 107 & 15.2 & 109 & 15.5 & 186 & 44.6 & 84 & 20.1 & 88.4 & 59.9 & 35.6 & 1.06 \\
\hline \multicolumn{13}{|c|}{$\dagger$ degree of polymerization and molecular weight as expected from the amount and ratio of reagents } \\
\hline$\$$ degree of polyr & & ular weight as & & m & & UV-detector & & & & & & \\
\hline
\end{tabular}

Weight ratios range from $3: 2$ to $1: 3$, suggesting morphologies in the lamellar and cylindrical regime. While the degree of polymerization of the PS block, as obtained from GPC measurements, matches the estimated molecular weight (assuming 100\% conversion), the measured degree of polymerization of the PTMA blocks is only approximately half as long as estimated, even though polymerization yields were almost quantitative. Measurements with polystyrene standards in THF as eluant (a good solvent for the PS block) might cause this deviation between calculated and observed molecular weight. Since the discrepancy is consistent in all samples of different composition, we assume the error to be systematic in nature and trust the composition to be approximately the calculated one (given the known ratio of monomer educts and the yield).

Comparing the intensities of the aromatic C-H peak at $697 \mathrm{~cm}^{-1}$ in IR spectroscopy data (Figure SI-1; intensities of all PS- $b$-PTMA polymers at this wavelength are equal since the intensity is normalized to this peak) with the intensities of carbonyl $(\mathrm{C}=\mathrm{O})$ or nitroxide $(\mathrm{N}-\mathrm{O} \cdot)$ peaks (at $1725 \mathrm{~cm}^{-1}$ and $1367 \mathrm{~cm}^{-1}$, respectively) confirms the order of PS-to-PTMA block ratios (smallest PS-to-PTMA block ratio in $\mathrm{PS}_{15}-b$-PTMA 45 , followed by $\mathrm{PS}_{45}-b-\mathrm{PTMA}_{45}$ and $\mathrm{PS}_{69}-b$ $\left.\mathrm{PTMA}_{45} \approx \mathrm{PS}_{35}-b-\mathrm{PTMA}_{22}\right){ }^{29,30,32}$ 
NMR spectroscopy and CV data (Figures SI-2 and SI-3 in the Supporting Information, respectively) also confirm the existence of stable radical groups in the final polymers (NMR data: aromatic $\underline{\mathrm{CH}}$ and $\mathrm{OCH}\left(\mathrm{CH}_{2}\right)_{2}$ peaks at approx. 6.3-7.2 ppm and $4.82 \mathrm{ppm} ; \mathrm{CV}$ : redox peaks at approx. $0.468 \mathrm{~V}$ vs. $\mathrm{Ag} / \mathrm{AgNO}_{3}$ ). Thermal analysis (Figure SI-4 in the Supporting Information) indicates glass transitions around $100^{\circ} \mathrm{C}$ and $150{ }^{\circ} \mathrm{C}$ and decomposition stability up to approximately $250^{\circ} \mathrm{C}$.

Structure Formation. Due to their block lengths, block ratios and dispersity, all block copolymers may be suited for the formation of ordered redox-active spots in a dense pattern or redox-active meshes. The kind of network can be controlled by the block copolymer composition, but structure formation may be suppressed and is susceptible to changes due to film preparation conditions or surface fields. We will discuss this in the remainder of this contribution. Figure 1 shows AFM phase images of the different polymers after spin-coating from solutions in chloroform.
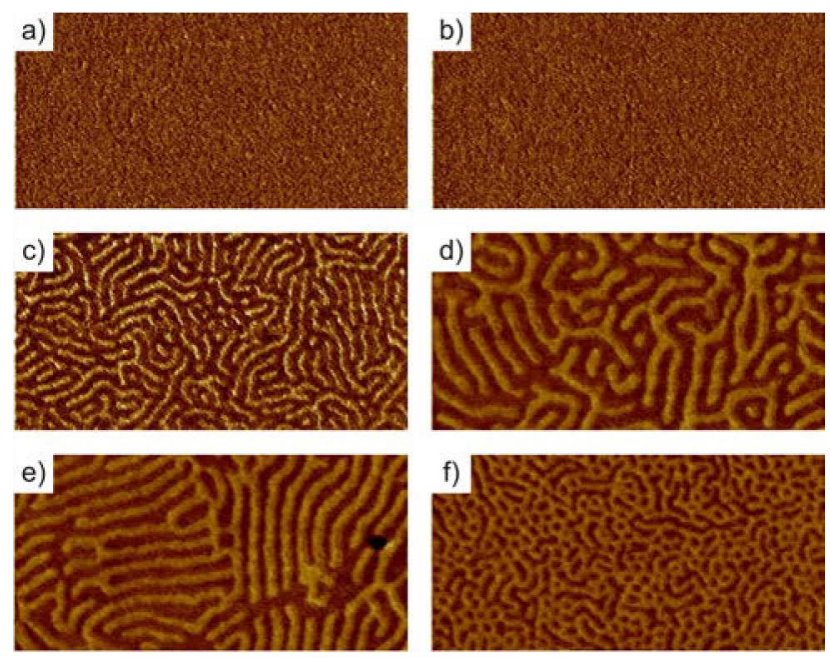

$250 \mathrm{~nm}$ 


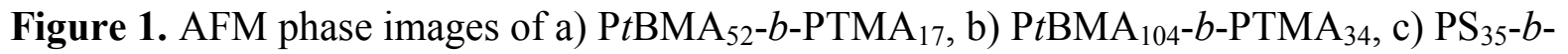
PTMA $_{22}$, d) $\mathrm{PS}_{69}-b-\mathrm{PTMA}_{45}$, e) $\mathrm{PS}_{45}-b$-PTMA 45, f) $\mathrm{PS}_{15}-b-\mathrm{PTMA}_{45}$ after spin-coating from solutions in chloroform. Corresponding topography images in the Supporting Information. The color coding bar $\left(\Delta \varphi=7.5^{\circ}\right)$ and scale bar correspond to all images.

Both PtBMA- $b$-PTMA films (Figures 1a,b) appear as uniformly colored surfaces in AFM topography or phase images, revealing a covering layer of the majority component (PtBMA). From the polymer block ratio (assuming similar density of both methacrylates), we would expect a spherical or cylindrical morphology in these polymers. This indicates that PTMA spheres in a PtBMA matrix may be buried underneath the film surface and hence indistinguishable in AFM images. PS- $b$-PTMA films show phase-separated structures without long-range order and negligible grain size after spin-coating. Assuming similar density of both blocks and that the volume fractions are comparable to weight fractions, we can denote the brighter areas in AFM phase images (also brighter in AFM topography images, see Supporting Information) to the PTMA block. Both polymers with a block ratio of 3:2 $\left(\mathrm{PS}_{35}-b-\mathrm{PTMA}_{22}\right.$ and $\mathrm{PS}_{69}-b-\mathrm{PTMA}_{45}$, Figures 1c and d, respectively) show bright stripes and few dots in a dark surface, denoting to a disordered morphology of preferentially flat-lying PTMA cylinders in a PS matrix. Upon decreasing the PS block size to a PS:PTMA ratio of 1:1 (PS $\mathrm{PS}_{45} b-\mathrm{PTMA}_{45}$, Figure 1e) and 1:3 $\left(\mathrm{PS}_{15}-b\right.$-PTMA 45 , Figure 1f), dark and bright stripes (Figure 1e) and dark dots and few lines in a bright matrix are observed. This indicates a disordered lamellar structure and disordered, mainly upright-standing PS cylinders in a PTMA matrix in Figures 1e and 1f, respectively.

Structures after film preparation by spin-coating, in addition to the block ratio, mainly depend on the selectivity of the spin-coating solvent and the fast drying rate from solution and are hence often disordered and not in thermodynamic equilibrium. Solubility parameters of PTMA in 
chloroform are unknown and hence the solvent selectivity in PS-b-PTMA polymers hard to calculate. We analyzed the selectivity of the blocks for selected solvents by monitoring the film thickness of homopolymer films during exposure to solvent vapor. Film preparation and annealing conditions were the same for PS and PTMA homopolymer films. In chloroform vapor, PS films swelled 1.65-fold under the chosen annealing conditions while PTMA swelled 1.91-fold (exactly the same conditions), which indicates that chloroform is a good solvent for both blocks with a preference for PTMA. This may explain the enrichment of PTMA domains at the film surface and formation of mainly flat-lying cylinders in $\mathrm{PS}_{35}-b-\mathrm{PTMA}_{22}$ and $\mathrm{PS}_{69}-b-\mathrm{PTMA}_{45}$ after spin-coating films from chloroform.

We note that phase separated block copolymer morphologies are observable after spin-coating, but domains are disordered with negligible or only small grain size. This is still significantly better when compared to previously published work on PTMA containing block copolymers. In the past, clear block copolymer morphologies were not observable after spin-coating ${ }^{7,14-16}$ and only emerged after thorough annealing processes. ${ }^{18-20}$ Even in similar PS-b-PTMA block copolymers, structures after spin-coating were significantly less ordered when the polymers were made by controlled radical procedures and hence exhibited higher PDI. ${ }^{20}$ We hence attribute the better order in our system to the lower dispersity compared to most published work on PTMA block copolymers.

Thermal Annealing. To present even more ordered structures in our PTMA block copolymer systems, we will discuss annealing techniques in the following section. Annealing at elevated temperatures or by exposure to solvent vapor can help to establish thermodynamic equilibrium. All polymers do not decompose below approx. $220^{\circ} \mathrm{C}$ (see Supporting Information). Temperatures above the glass transition temperatures and below the decomposition temperatures 
of both blocks, and hence in the range between $160{ }^{\circ} \mathrm{C}$ and $220{ }^{\circ} \mathrm{C}$, seem suitable for thermal annealing. However, Gohy et al. did not observe phase separated structures in PS- $b$-PTMA block copolymers after thermal annealing at $200{ }^{\circ} \mathrm{C}$ for $24 \mathrm{~h}$ or after rapid thermal annealing to $190{ }^{\circ} \mathrm{C}$ while keeping the samples at this temperature for $60 \mathrm{~s} .{ }^{20}$ Even though the films are not decomposed at this temperature, reactions involving the nitroxide radicals may occur at long treatment times, especially crosslinking reactions may happen. Hence, we investigated thermal annealing at $200{ }^{\circ} \mathrm{C}$ for intermediate annealing times between the times indicated above (in our case we used $20 \mathrm{~min}$ and $150 \mathrm{~min}$ ). AFM phase images of the resulting structures are displayed in Figures 2 and 3; the corresponding topography images are enclosed in the Supporting Information.
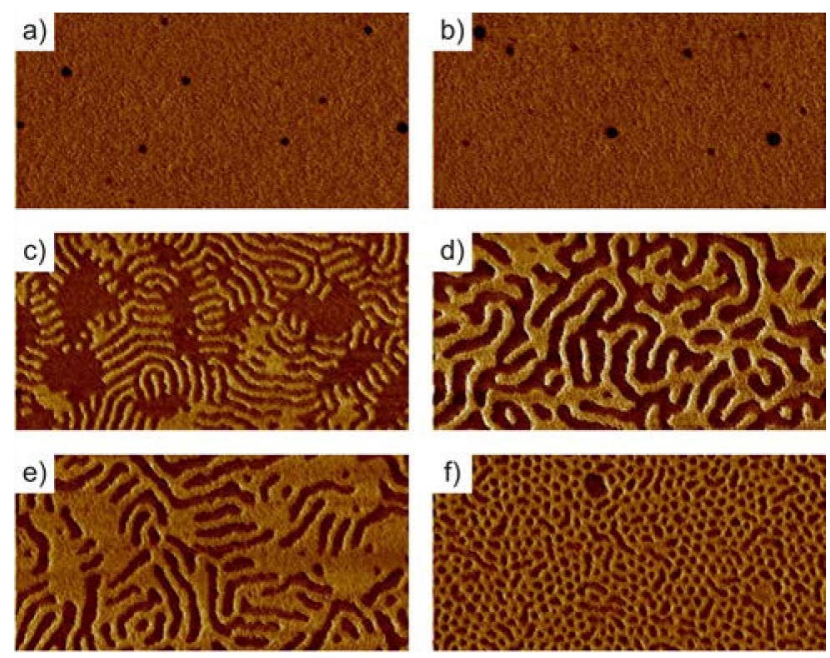

$250 \mathrm{~nm}$

Figure 2. AFM phase images of a) $\mathrm{P} \mathrm{BMA}_{52}-b-\mathrm{PTMA}_{17}$, b) $\left.\mathrm{P}_{2} \mathrm{BMA}_{104}-b-\mathrm{PTMA}_{34}, \mathrm{c}\right) \mathrm{PS}_{35}-b-$ $\mathrm{PTMA}_{22}$, d) $\mathrm{PS}_{69}-b-\mathrm{PTMA}_{45}$, e) $\mathrm{PS}_{45}-b-\mathrm{PTMA}_{45}$, f) $\mathrm{PS}_{15}-b-\mathrm{PTMA}_{45}$ after spin-coating from solutions in chloroform and subsequent thermal annealing at $200{ }^{\circ} \mathrm{C}$ for $20 \mathrm{~min}$. Corresponding topography images in the Supporting Information. The color coding bar $\left(\Delta \varphi=10^{\circ}\right)$ and scale bar correspond to all images. 

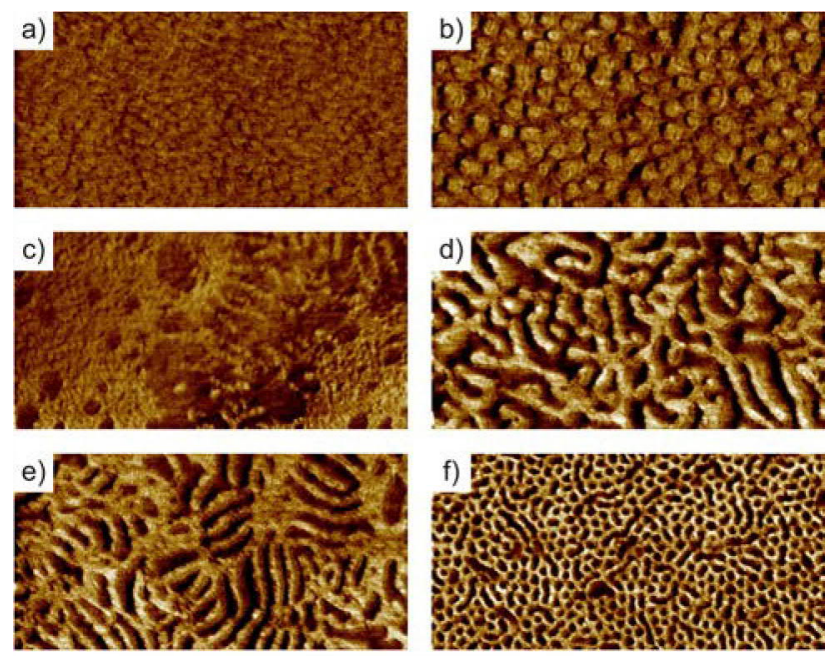

$250 \mathrm{~nm}$

Figure 3. AFM phase images of a) $\mathrm{P}_{2} \mathrm{BMA}_{52}-b-\mathrm{PTMA}_{17}$, b) $\left.\mathrm{P}_{2} \mathrm{BMA}_{104}-b-\mathrm{PTMA}_{34}, \mathrm{c}\right) \mathrm{PS}_{35}-b-$ PTMA $_{22}$, d) $\mathrm{PS}_{69}-b-\mathrm{PTMA}_{45}$, e) $\mathrm{PS}_{45}-b$-PTMA 45, f) $\mathrm{PS}_{15}-b-\mathrm{PTMA}_{45}$ after spin-coating from solutions in chloroform and subsequent thermal annealing at $200{ }^{\circ} \mathrm{C}$ for $150 \mathrm{~min}$. Corresponding topography images in the Supporting Information. The color coding bar $\left(\Delta \varphi=10^{\circ}\right)$ and scale bar correspond to all images.

After thermal annealing for 20 min, PtBMA- $b$-PTMA films show a featureless surface, similar to the situation after spin-coating (Figures $2 \mathrm{a}, \mathrm{b}) . \mathrm{PS}_{35}-b-\mathrm{PTMA}_{22}$ and $\mathrm{PS}_{69}-b-\mathrm{PTMA}_{45}$

(Figures 2c,d) have a surface composed of stripes and uniformly colored areas in AFM phase images, denoting a transition from the cylindrical to the lamellar morphology, which is the equilibrium morphology at the 3:2 block ratio, during annealing. Different surface enrichment of the blocks (more PS at the surface in $\mathrm{PS}_{35}-b-\mathrm{PTMA}_{22}$ and more PTMA at the surface in $\mathrm{PS}_{69}-b$ PTMA $_{45}$ ) may be due to slightly different film thickness. In the former, grains of stacked lamellae are observable. This may indicate faster ordering processes due to the lower overall molecular weight when compared to $\mathrm{PS}_{69}-b-\mathrm{PTMA}_{45}$. The mixed uniform and striped surface in $\mathrm{PS}_{45}-b-\mathrm{PTMA}_{45}$ (Figure 2e) corresponds to a lamellar morphology (as expected for the 1:1 block 
ratio in thermodynamic equilibrium) without preferential lamella orientation. $\mathrm{PS}_{15}-b-\mathrm{PTMA}_{45}$ films show, just like after spin-coating, a mainly dotted surface structure (Figure 2f) indicating a cylindrical morphology. After thermal annealing for $20 \mathrm{~min}$, however, the cylinders are better ordered in comparison to the as-spin coated state, and small grains of hexagonally packed cylinders are observable.

Longer thermal annealing, for $150 \mathrm{~min}$ total annealing time, does not lead to better order in the PS- $b$-PTMA samples (Figure 3c-f). In contrast, while structures are similar to the case of $20 \mathrm{~min}$ thermal annealing (only $\mathrm{PS}_{35}-b$ - $\mathrm{PTMA}_{22}$ reorganized to a higher proportion of flat-lying lamellae), now domain spacing looks less uniform, indicating damage to the polymer films. Especially $\mathrm{PS}_{15}-b-\mathrm{PTMA}_{45}$ exhibits an irregular pattern of dots and lines which may denote severe crosslinking. This may explain why Gohy et al. observed no phase separated structures after $24 \mathrm{~h}$ thermal annealing at $200{ }^{\circ} \mathrm{C} .{ }^{20}$

In PtBMA-b-PTMA films, dotted structures are observable after 150 min thermal annealing, especially for the larger polymer $\mathrm{P}_{\mathrm{BMA}} \mathrm{A}_{104}-b-\mathrm{PTMA}_{34}$. The block ratio of 3:1 (from weight fractions) indicates a cylindrical or micellar structure in which PTMA is embedded in a PtBMA matrix. No striped patterns are visible, denoting to either completely upright standing PTMA cylinders in PtBMA or PTMA micelles. The different surface preferences when compared to shorter annealing times however might indicate chemical changes of the material, leading to a different surface energy of the former PTMA block.

Thermal annealing experiments indicate that in contrast to previous observations, structure formation is possible, most prominently observed in Figures 2c,d, in which non-equilibrium structures after spin-coating were transformed to the equilibrium morphology. This however is 
only the case for rather short annealing times. Crosslinking of the PTMA block at elevated temperatures may lead to irreversible film damage as indicated from AFM images. Large ordered grains are not observed in neither of the polymers under investigation, probably due to film damage at prolonged thermal annealing times. We will hence refrain from thermal annealing and continue on with solvent vapor annealing in the following.

Solvent Vapor Annealing. From Figures 1-3, we see that $\mathrm{PS}_{15}-b-\mathrm{PTMA}_{45}$ might be suited for forming a dense mesh of a nitroxide containing polymer around polystyrene cylinders. Structures after spin-coating were however not long-range ordered, and after thermal annealing crosslinking potentially leads to irreversible damage, also preventing long-range order. We will hence focus on this polymer for describing solvent influences of spin-coating and solvent vapor annealing as well as film thickness. By avoiding thermal treatment and switching to solvent vapor annealing we aim to induce mobility without introducing potential film damage.

Chloroform, which we used as a spin-coating solvent in all of the above described experiments, is slightly selective for the PTMA block as indicated by monitoring the film thickness during controlled solvent vapor annealing. Toluene has the opposite effect: when swelling PS and PTMA homopolymer films in a controlled toluene vapor atmosphere, comparable conditions resulted in swelling 1.48 -fold and 1.38 -fold, respectively. With toluene and chloroform, we hence identified two solvents which are good solvents for both blocks but with opposite preferences. Figure 4 summarizes the influence of both on $\mathrm{PS}_{15}-b-\mathrm{PTMA}_{45}$ structure formation. 

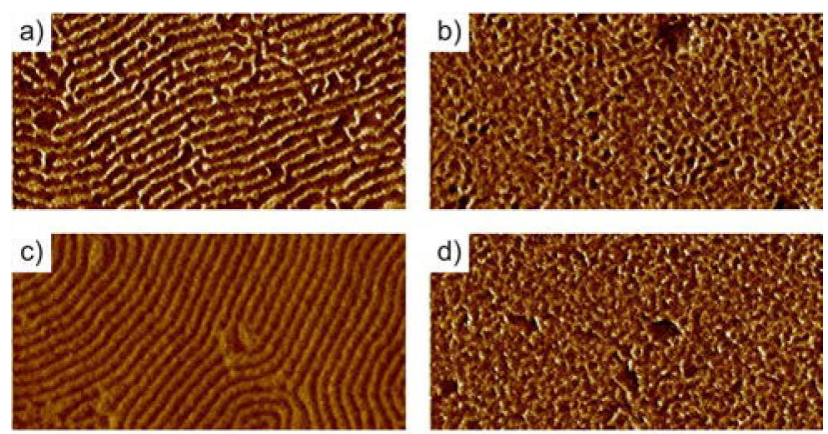

$250 \mathrm{~nm}$

Figure 4. AFM phase images of $\mathrm{PS}_{15}-b-\mathrm{PTMA}_{45}$ films after spin-coating from chloroform $(\mathrm{a}, \mathrm{b})$ or toluene $(\mathrm{c}, \mathrm{d})$ and subsequent solvent vapor annealing in chloroform $(\mathrm{a}, \mathrm{c})$ or toluene vapor $(b, d)$. Corresponding topography images in the Supporting Information. The color coding bar $\left(\Delta \varphi=5^{\circ}\right)$ and scale bar correspond to all images.

All films were spin-coated from solutions with the same polymer concentration $\left(10 \mathrm{mg} \mathrm{mL}^{-1}\right)$. Still, structures after chloroform (Figure 4a,c) or toluene (Figure 4b,d) vapor annealing differ in order and regularity. In general, toluene vapor annealing did not lead to clear block copolymer morphologies while after chloroform vapor annealing, (preferentially flat-lying) cylinders could be concluded from the mainly striped AFM phase images. Order is best for films spin-coated from toluene and subsequently annealed in chloroform vapor (Figure 4c), which might be explained by the lower selectivity of the spin-coating solvent (and hence the structure expected to be closer to the equilibrium structure after spin-coating) and higher vapor pressure of the annealing solvent (and hence higher mobility during annealing). PS cylinders in a PTMA matrix were preferentially flat-lying after this annealing process which may be caused by the change in film-thickness compared to above described experiments: while spin-coating $10 \mathrm{mg} \mathrm{mL}^{-1}$ solutions from chloroform leads to approx. $85 \mathrm{~nm}$ to $95 \mathrm{~nm}$ thick films for all described 
polymers, the same concentration in toluene results in only approx. $50 \mathrm{~nm}$ film thickness ( $48 \mathrm{~nm}$ for Figure $4 \mathrm{c})$.

Different film thickness in cylindrical block copolymers greatly influences the cylinder orientation. ${ }^{33}$ We hence applied the same spin-coating conditions to $\mathrm{PS}_{15}-b-\mathrm{PTMA}_{45}$ solutions in toluene with changing polymer concentration and annealed them like in Figure $4 \mathrm{c}$, resulting in structures as summarized in Figure 5.
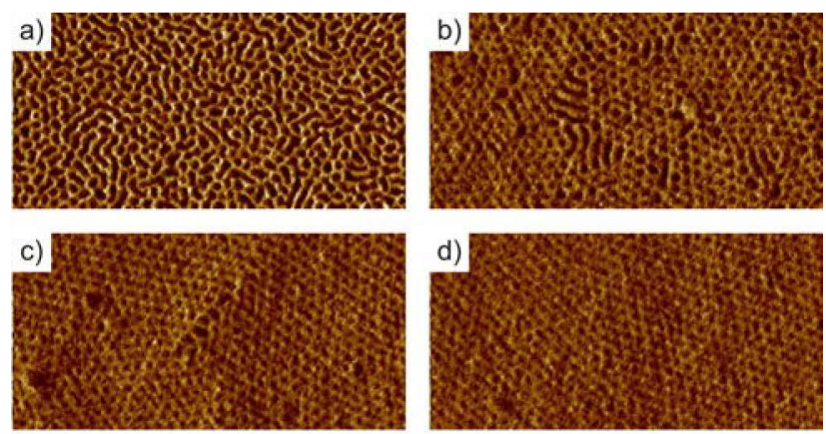

$250 \mathrm{~nm}$

Figure 5. AFM phase images of $\mathrm{PS}_{15}-b-\mathrm{PTMA}_{45}$ films after spin-coating from toluene and subsequent solvent vapor annealing in chloroform. Changing film thickness as a result of different concentration of the spin-coating solution: a) $\sim 19 \mathrm{~nm}$; b) $\sim 43 \mathrm{~nm}$; c) $\sim 85 \mathrm{~nm}$; d) $\sim 253 \mathrm{~nm}$. Corresponding topography images in the Supporting Information. The color coding bar $\left(\Delta \varphi=3^{\circ}\right)$ and scale bar correspond to all images.

In very thin films (Figure 5a, film thickness $\sim 19 \mathrm{~nm}$ ), a disordered mixed layer of PS and PTMA domains is visible. The film thickness is thinner than the equilibrium cylinder spacing $(\sim 31 \mathrm{~nm}$ from AFM images in Figures 4c and 5c). Brush layers of this film thickness are expected beneath the structures in Figures $4 \mathrm{c}$ and $5 \mathrm{~b}-\mathrm{d}$. With increasing film thickness to approx. $43 \mathrm{~nm}$ (Figure 5b), a mainly dotted and partially striped surface denotes to a mixture of upright- 
standing and flat-lying cylinders. The film thickness is thinner than a monolayer of cylinders $(\sim 31 \mathrm{~nm})$ above the brush layer (approx. $19 \mathrm{~nm}$ from Figure 5a), promoting perpendicular orientation of the cylinder axis with respect to the surface. Only once the film thickness reaches $\sim 48 \mathrm{~nm}$ (Figure 4c), confinement conditions support one layer of flat-lying cylinders above the brush layer. In all thicker films (Figures $5 \mathrm{c}$ and d, $\sim 85 \mathrm{~nm}$ and $\sim 253 \mathrm{~nm}$, respectively), pure dotted AFM images indicate upright-standing cylinders. They are hexagonally ordered within grains of several hundred nanometers in diameter. Within these grains, regular hexagonal nitroxide containing meshes are present.

Long-Range Alignment. In order to increase the grain size, we used substrates with lithographically patterned regular trenches (400 nm wide). Since in thick films upright-standing cylinders resulted irrespective of the film thickness (Figure 5c,d), we expected the change in film thickness upon film formation on physically patterned surfaces not to influence cylinder orientation with respect to the surface. Figure 6 shows representative AFM images of the resulting films after chloroform vapor annealing.
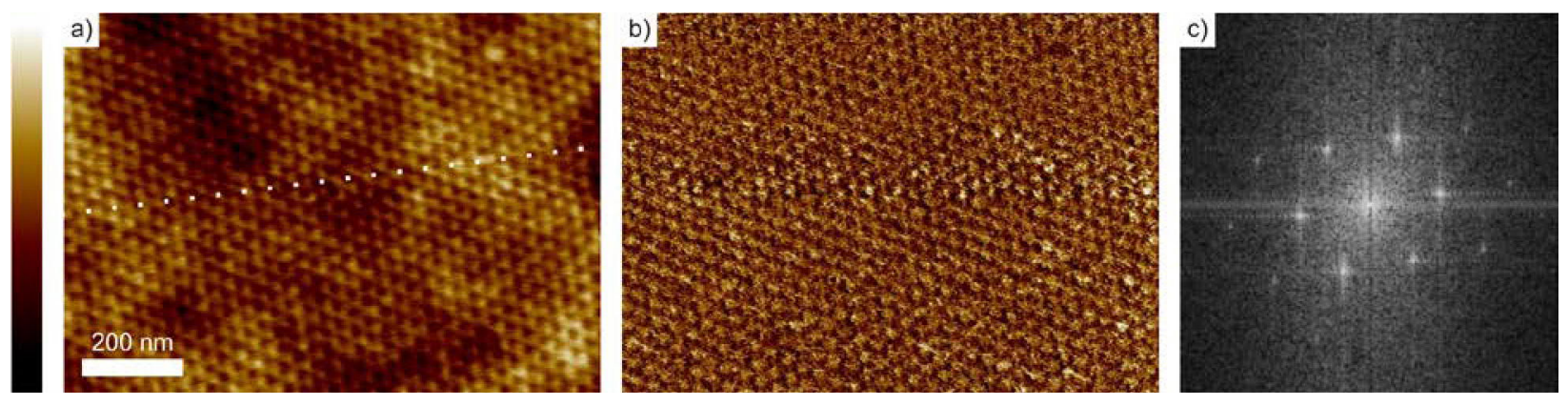

Figure 6. AFM topography (a) and phase (b) images of a $\mathrm{PS}_{15}-b$-PTMA $\mathrm{A}_{45}$ film after spin-coating from toluene and subsequent solvent vapor annealing in chloroform. c) Fourier transform of a square cutout of (a). The white dotted line in (a) indicates an edge of the trenches in the 
substrate. The color coding bar shows a range of $\Delta \mathrm{z}=3 \mathrm{~nm}$ (a) and $\Delta \varphi=5^{\circ}$ (b), respectively. The scale bar corresponds to both AFM images.

A flat surface (height scale in Figure 6a is only $\Delta \mathrm{z}=3 \mathrm{~nm}$ ) indicates that the trenched substrate does not introduce terrace formation. This has already been indicated from Figure 5 since cylinders are organized completely upright-standing irrespective of the film thickness above a cylindrical monolayer. Block copolymer cylinders organize in a large-scale defect free manner on the trenched substrate as also shown by Fourier transform of the AFM images (Figure 6c). The film surface is composed of a mixed composition of PS and PTMA, resulting in a regular PTMA mesh with a mesh size of only approx. $16 \mathrm{~nm}$ (half pitch, from AFM images). Alignment is defect-free in the micrometer range, which indicates that the organizing effect of trenched substrates traverses several hundred nanometers away from the edges.

\section{CONCLUSIONS}

In conclusion, we have presented a way to fabricate highly ordered nitroxide-containing nanomeshes. Block copolymers in which one block contains stable nitroxide radicals in every repeating unit were synthesized by sequential anionic polymerization. The resulting polymers cover a large range of conventional block copolymer morphologies and self-aggregate into ordered patterns after spin-coating and advanced thermal or solvent vapor annealing. The dimensions of ordered grains were enlarged by using macroscopically pre-structured substrates. The resulting hexagonal meshes feature a half pitch of approx. $16 \mathrm{~nm}$, stable nitroxide groups in the mesh and aligned orientation irrespective of the film thickness (above a limiting minimum thickness). After detaching the ordered polymer films and etching or dissolution of the auxiliary 
polystyrene domains, regular functional membranes or organic redox cathodes may be accessible.

\section{ASSOCIATED CONTENT}

Supporting Information. IR, NMR, CV, DSC, and TGA data of the polymers, and AFM topography images. This material is available free of charge via the Internet at http://pubs.acs.org.

\section{AUTHOR INFORMATION}

\section{Corresponding Author}

* Tel +49 331-567-9552, Email Clemens.Liedel@mpikg.mpg.de (C. L.); Tel 607-255-8417, Email Christopher.Ober@cornell.edu (C. K. O.)

\section{Notes}

The authors declare no competing financial interest.

\section{ACKNOWLEDGMENT}

We thank Alicia Cintora and Steffen Tröger-Müller for help in the laboratory. We appreciate fruitful discussion with Gregory D. Fuchs, Myungwoon Kim and Austin Moehle. Trenched substrates were supplied by Jing Jiang. C. L. acknowledges financial support by the Deutsche Forschungsgemeinschaft (German Research Foundation, Forschungsstipendium Li 2526). AFM 
measurements were performed at the Cornell NanoScale Facility, a member of the National Nanotechnology Infrastructure Network, which is supported by the National Science Foundation (grant ECCS-0335765). For GPC, TGA and DCS measurements, this work made use of the Cornell Center for Materials Research Shared Facilities which are supported through the NSF MRSEC program (DMR-1120296).

\section{REFERENCES}

(1) Zhou, Z.; Liu, L. TEMPO and its Derivatives: Synthesis and Applications. Curr. Org. Chem. 2014, 18, 459-474.

(2) Hawker, C. J.; Bosman, A. W.; Harth, E. New Polymer Synthesis by Nitroxide Mediated Living Radical Polymerizations. Chem. Rev. 2001, 101, 3661-3688.

(3) Gnewuch, C. T.; Sosnovsky, G. A Critical Appraisal of the Evolution of N-Nitrosoureas as Anticancer Drugs. Chem. Rev. 1997, 97, 829-1014.

(4) Segalman, R. A. Patterning with Block Copolymer Thin Films. Mater. Sci. Eng. Reports $\mathbf{2 0 0 5}, 48,191-226$.

(5) Nie, Z.; Kumacheva, E. Patterning Surfaces with Functional Polymers. Nat. Mater. 2008, 7, 277-290.

(6) Stadermann, J.; Riedel, M.; Komber, H.; Simon, F.; Voit, B. Functionalized Block Copolymers for Preparation of Reactive Self-Assembled Surface Patterns. J. Polym. Sci. Part A Polym. Chem. 2012, 50, 1351-1361.

(7) Suga, T.; Sakata, M.; Aoki, K.; Nishide, H. Synthesis of Pendant Radical- and Ion- 
Containing Block Copolymers via Ring-Opening Metathesis Polymerization for Organic Resistive Memory. ACS Macro Lett. 2014, 3, 703-707.

(8) Suga, T.; Aoki, K.; Nishide, H. Ionic Liquid-Triggered Redox Molecule Placement in Block Copolymer Nanotemplates toward an Organic Resistive Memory. ACS Macro Lett. 2015, 4, 892-896.

(9) Nakahara, K.; Iwasa, S.; Satoh, M.; Morioka, Y.; Iriyama, J.; Suguro, M.; Hasegawa, E. Rechargeable Batteries with Organic Radical Cathodes. Chem. Phys. Lett. 2002, 359, $351-354$.

(10) Oyaizu, K.; Nishide, H. Radical Polymers for Organic Electronic Devices: A Radical Departure from Conjugated Polymers? Adv. Mater. 2009, 21, 2339-2344.

(11) Nakahara, K.; Oyaizu, K.; Nishide, H. Organic Radical Battery Approaching Practical Use. Chem. Lett. 2011, 40, 222-227.

(12) Janoschka, T.; Hager, M. D.; Schubert, U. S. Powering up the Future: Radical Polymers for Battery Applications. Adv. Mater. 2012, 24, 6397-6409.

(13) Oyaizu, K.; Tatsuhira, H.; Nishide, H. Facile Charge Transport and Storage by a TEMPOPopulated Redox Mediating Polymer Integrated with Polyaniline as Electrical Conducting Path. Polym. J. 2015, 47, 212-219.

(14) Zhuang, X.; Xiao, C.; Oyaizu, K.; Chikushi, N.; Chen, X.; Nishide, H. Synthesis of Amphiphilic Block Copolymers Bearing Stable Nitroxyl Radicals. J. Polym. Sci. Part A Polym. Chem. 2010, 48, 5404-5410.

(15) Hauffman, G.; Rolland, J.; Bourgeois, J.-P.; Vlad, A.; Gohy, J.-F. Synthesis of Nitroxide- 
Containing Block Copolymers for the Formation of Organic Cathodes. J. Polym. Sci. Part A Polym. Chem. 2013, 51, 101-108.

(16) Uemukai, T.; Hioki, T.; Ishifune, M. Thermoresponsive and Redox Behaviors of Poly(Nisopropylacrylamide)-Based Block Copolymers Having TEMPO Groups as Their Side Chains. Int. J. Polym. Sci. 2013, 2013, 196145.

(17) Hauffman, G.; Maguin, Q.; Bourgeois, J.-P.; Vlad, A.; Gohy, J.-F. Micellar Cathodes from Self-Assembled Nitroxide-Containing Block Copolymers in Battery Electrolytes. Macromol. Rapid Commun. 2014, 35, 228-233.

(18) Liedel, C.; Moehle, A.; Fuchs, G. D.; Ober, C. K. Block Copolymers with Stable Radical and Fluorinated Groups by ATRP. MRS Commun. 2015, 5, 441-446.

(19) Rostro, L.; Baradwaj, A. G.; Muller, A. R.; Laster, J. S.; Boudouris, B. W. Synthesis and Thin-Film Self-Assembly of Radical-Containing Diblock Copolymers. MRS Commun. 2015, 5, 257-263.

(20) Hauffman, G.; Vlad, A.; Janoschka, T.; Schubert, U. S.; Gohy, J.-F. Nanostructured Organic Radical Cathodes from Self-Assembled Nitroxide-Containing Block Copolymer Thin Films. J. Mater. Chem. A 2015, 3, 19575-19581.

(21) Rostro, L.; Baradwaj, A. G.; Boudouris, B. W. Controlled Radical Polymerization and Quantification of Solid State Electrical Conductivities of Macromolecules Bearing Pendant Stable Radical Groups. ACS Appl. Mater. Interfaces 2013, 5, 9896-9901.

(22) Griffith, O. H.; Keana, J. F. W.; Rottschaefer, S.; Warlick, T. A. Preparation and Magnetic Resonance of Nitroxide Polymers. J. Am. Chem. Soc. 1967, 89, 5072. 
(23) Yonekuta, Y.; Susuki, K.; Oyaizu, K.; Honda, K.; Nishide, H. Battery-Inspired, Nonvolatile, and Rewritable Memory Architecture: a Radical Polymer-Based Organic Device. J. Am. Chem. Soc. 2007, 129, 14128-14129.

(24) Sukegawa, T.; Omata, H.; Masuko, I.; Oyaizu, K.; Nishide, H. Anionic Polymerization of 4-Methacryloyloxy-TEMPO Using an MMA-Capped Initiator. ACS Macro Lett. 2014, 3, $240-243$.

(25) Sukegawa, T.; Masuko, I.; Oyaizu, K.; Nishide, H. Expanding the Dimensionality of Polymers Populated with Organic Robust Radicals toward Flow Cell Application: Synthesis of TEMPO-Crowded Bottlebrush Polymers Using Anionic Polymerization and ROMP. Macromolecules 2014, 47, 8611-8617.

(26) Albert, J. N. L.; Epps, T. H. Self-Assembly of Block Copolymer Thin Films. Mater. Today 2010, 13, 24-33.

(27) Hu, H.; Gopinadhan, M.; Osuji, C. O. Directed Self-Assembly of Block Copolymers: A Tutorial Review of Strategies for Enabling Nanotechnology with Soft Matter. Soft Matter 2014, 10, 3867-3889.

(28) Allgaier, J.; Finkelmann, H. Anionic Polymerization of 4-Methacryloyloxy-2,2,6,6Tetramethylpiperidin-1-Oxyl and the Magnetic Properties of the Polymer. Macromol. Rapid Commun. 1993, 14, 267-271.

(29) Guo, W.; Yin, Y.-X.; Xin, S.; Guo, Y.-G.; Wan, L.-J. Superior Radical Polymer Cathode Material with a Two-Electron Process Redox Reaction Promoted by Graphene. Energy Environ. Sci. 2012, 5, 5221-5225. 
(30) Wang, Y.; Song, X.; Shao, S.; Zhong, H.; Lin, F. An Efficient, Soluble, and Recyclable Multiwalled Carbon Nanotubes-Supported TEMPO for Oxidation of Alcohols. RSC Adv. 2012, 2, 7693-7698.

(31) López-Peña, H. A.; Hernández-Muñoz, L. S.; Frontana-Uribe, B. A.; González, F. J.; González, I.; Frontana, C.; Cardoso, J. Tacticity Influence on the Electrochemical Reactivity of Group Transfer Polymerization-Synthesized PTMA. J. Phys. Chem. B 2012, $116,5542-5550$.

(32) Olmos, D.; Martín, E. V.; González-Benito, J. New Molecular-Scale Information on Polystyrene Dynamics in PS and PS-BaTiO3 Composites from FTIR Spectroscopy. Phys. Chem. Chem. Phys. 2014, 16, 24339-24349.

(33) Knoll, A.; Horvat, A.; Lyakhova, K. S.; Krausch, G.; Sevink, G. J. A.; Zvelindovsky, A. V.; Magerle, R. Phase Behavior in Thin Films of Cylinder-Forming Block Copolymers. Phys. Rev. Lett. 2002, 89, 035501. 


\section{Supplementary Information:}

Table SI-1: P $t$ BMA- $b$-PTMA block copolymers.

\begin{tabular}{|c|c|c|c|c|c|c|c|c|c|c|c|c|}
\hline \multirow[t]{3}{*}{ sample } & \multicolumn{4}{|c|}{ P $t$ BMA block } & \multicolumn{4}{|c|}{ PTMA block } & \multicolumn{4}{|c|}{ P $t$ BMA- $b$-PTMA block copolymer } \\
\hline & \multicolumn{2}{|c|}{ calculated $^{\dagger}$} & \multicolumn{2}{|c|}{ measured $(\mathrm{GPC})^{\ddagger}$} & \multicolumn{2}{|c|}{ calculated $^{\dagger}$} & \multicolumn{2}{|c|}{ measured $(\mathrm{GPC})^{\ddagger}$} & \multirow{2}{*}{$\begin{array}{c}\text { yield } \\
/ \%\end{array}$} & \multirow{2}{*}{$\begin{array}{c}\mathrm{M}_{\mathrm{n}, \mathrm{th}}^{\dagger} \\
/ \mathrm{kg} \mathrm{mol}^{-1}\end{array}$} & \multirow{2}{*}{$\begin{array}{c}\mathrm{M}_{\mathrm{n}, \mathrm{GPC}^{\ddagger}} \\
/ \mathrm{kg} \mathrm{mol}^{-1}\end{array}$} & \multirow{2}{*}{$\begin{array}{l}\mathrm{M}_{\mathrm{w}} / \mathrm{M}_{\mathrm{n}} \\
(\mathrm{GPC})\end{array}$} \\
\hline & $\mathrm{DP}$ & $\mathrm{M}_{\mathrm{n}} / \mathrm{kg} \mathrm{mol}^{-1}$ & $\mathrm{DP}$ & $\mathrm{M}_{\mathrm{n}} / \mathrm{kg} \mathrm{mol}^{-1}$ & $\mathrm{DP}$ & $\mathrm{M}_{\mathrm{n}} / \mathrm{kg} \mathrm{mol}^{-1}$ & $\mathrm{DP}$ & $\mathrm{M}_{\mathrm{n}} / \mathrm{kg} \mathrm{mol}^{-1}$ & & & & \\
\hline $\mathrm{PTMA}_{20}$ & - & - & - & - & 84 & 20.1 & 54 & 13.5 & 77.1 & 20.1 & 13.5 & 1.04 \\
\hline $\mathrm{P}_{t} \mathrm{BMA}_{23}-b-\mathrm{PTMA}_{48}$ & 160 & 22.8 & 156 & 22.2 & 198 & 47.6 & 215 & 51.6 & 86.0 & 70.4 & 73.8 & 1.12 \\
\hline $\mathrm{P} t \mathrm{BMA}_{23}-b-\mathrm{PTMA}_{22}$ & 158 & 22.5 & 156 & 22.2 & 93 & 22.3 & 114 & 27.5 & 87.4 & 44.8 & 49.7 & 1.05 \\
\hline $\mathrm{P}_{t} \mathrm{BMA}_{52}-b-\mathrm{PTMA}_{22}$ & 364 & 51.8 & 372 & 52.8 & 93 & 22.3 & 129 & 31.0 & 95.2 & 74.1 & 83.8 & 1.07 \\
\hline $\mathrm{P}_{t} \mathrm{BMA}_{52}-b-\mathrm{PTMA}_{17}$ & 364 & 51.8 & 362 & 51.5 & 70 & 16.7 & 71 & 17.1 & 98.1 & 68.5 & 68.5 & 1.08 \\
\hline $\mathrm{P} \mathrm{BMA}_{104}-b-\mathrm{PTMA}_{34}$ & 728 & 103.5 & 759 & 107.9 & 139 & 33.5 & 228 & 54.8 & 96.4 & 137.0 & 162.7 & 1.13 \\
\hline
\end{tabular}

$\dagger$ degree of polymerization and molecular weight as expected from the amount and ratio of reagents

$\ddagger$ degree of polymerization and molecular weight as calculated from GPC in THF with a UV-detector
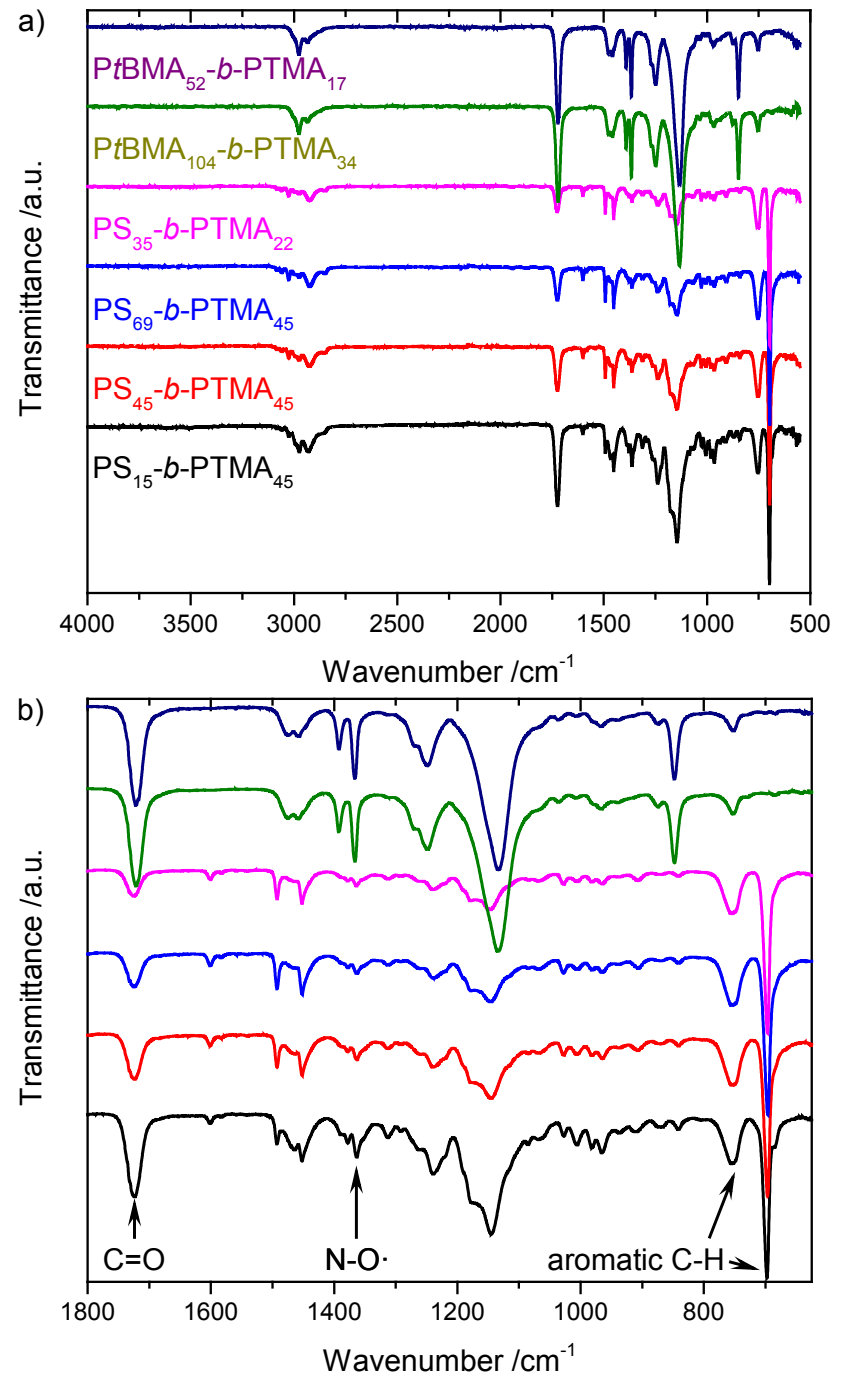
Figure SI-1: FT-IR spectra of the polymers described in this contribution. Assignment of the graphs to the individual polymers as denoted in the figure. (b) is a larger magnification of (a). The intensities of the PS-containing polymers were normalized to the out of plane aromatic C-H vibration at $697 \mathrm{~cm}^{-1} .{ }^{1-3}$

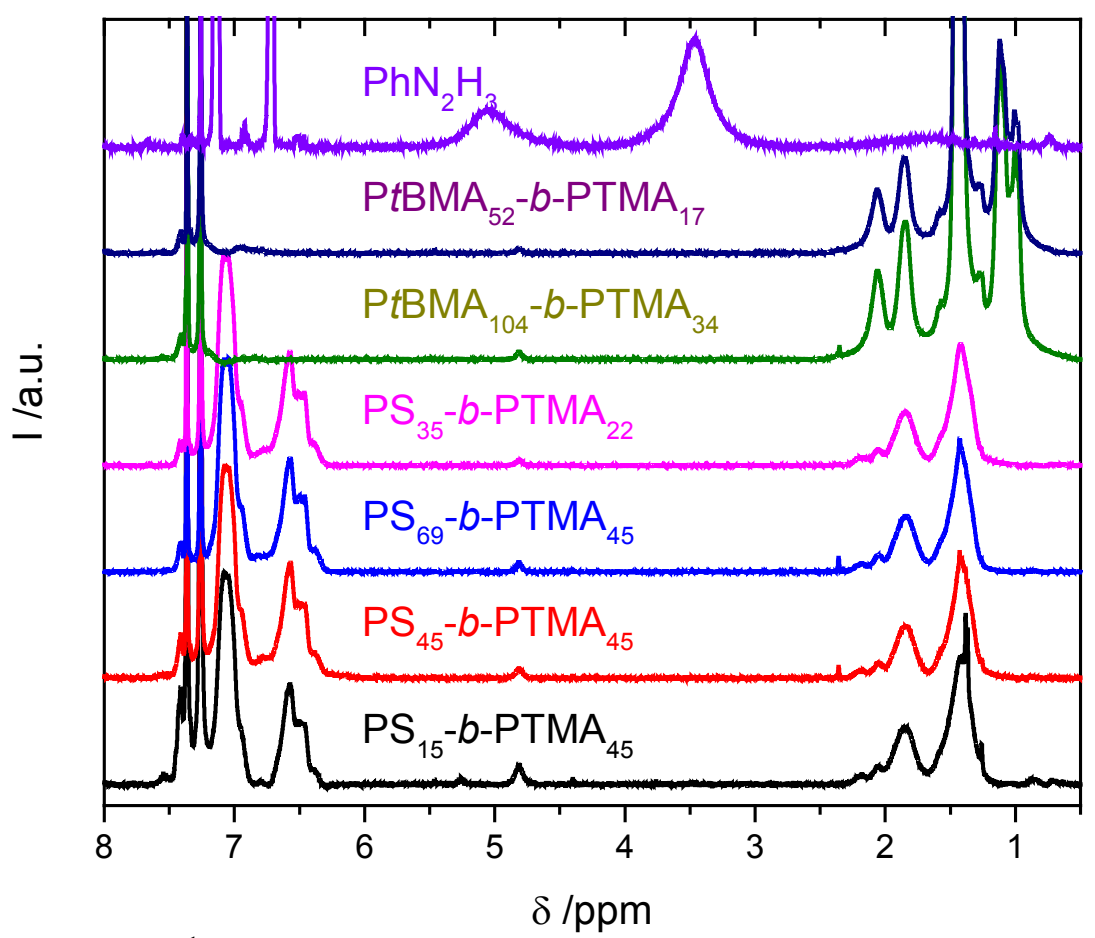

Figure SI-2: ${ }^{1} \mathrm{H}-\mathrm{NMR}$ spectra of the polymers described in this contribution after reduction with phenylhydrazine in $\mathrm{CDCl}_{3}$. Assignment of the graphs to the individual polymers as denoted in the figure.

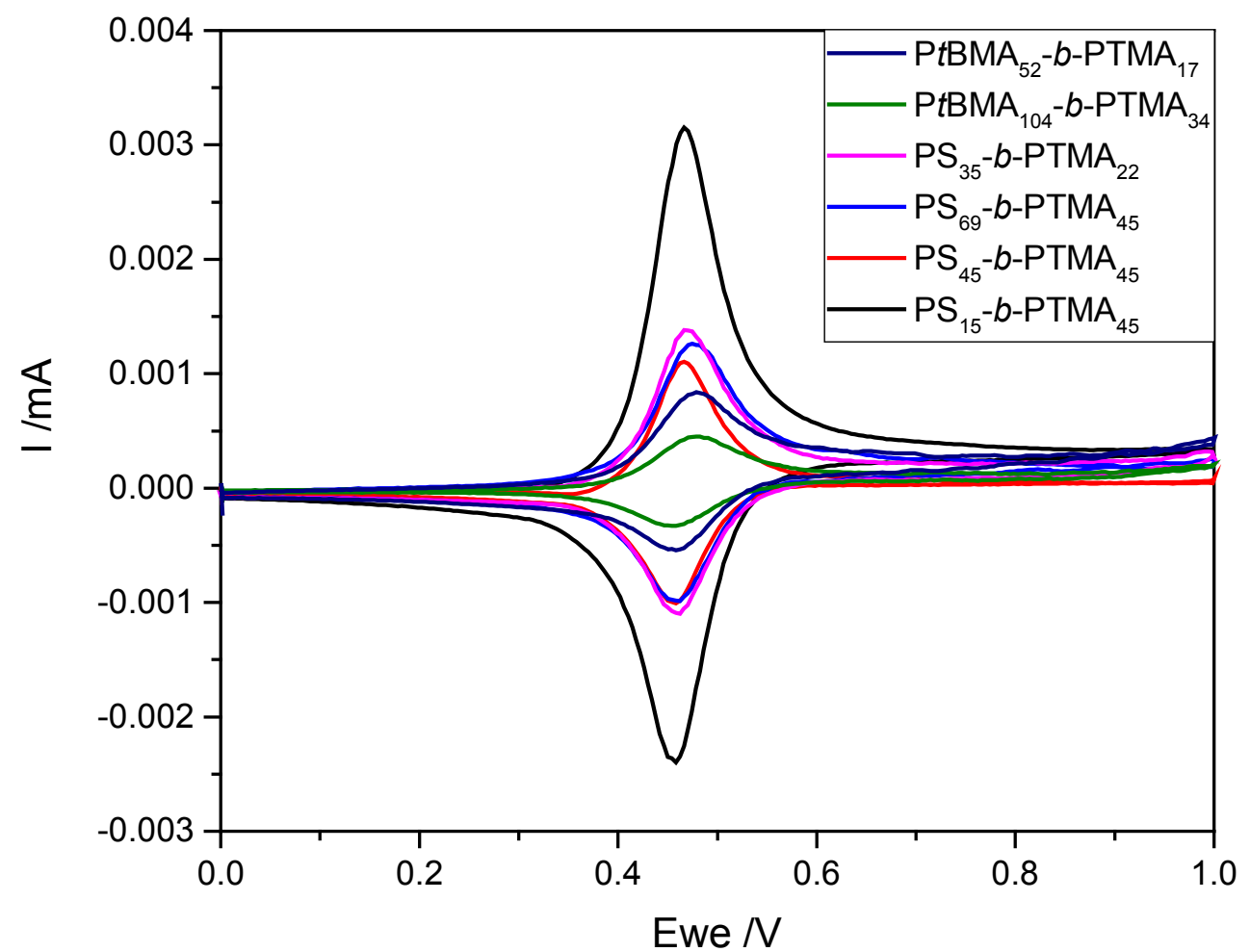

Figure SI-3: Cyclovoltammetry plots of the polymers described in this contribution in acetonitrile with $\mathrm{NBu}_{4} \mathrm{PF}_{6}$ 
$(0.1 \mathrm{M})$ as auxiliary electrolyte. Assignment of the graphs to the individual polymers as denoted in the figure. WE: GCE, CE: Pt wire, RE: $\mathrm{Ag} / \mathrm{AgNO}_{3}(0.01 \mathrm{M})+\mathrm{NBu}_{4} \mathrm{PF}_{6}(0.1 \mathrm{M})$, scan rate $100 \mathrm{mV} \mathrm{s}{ }^{-1}$. The polymers did not dissolve completely in acetonitrile.
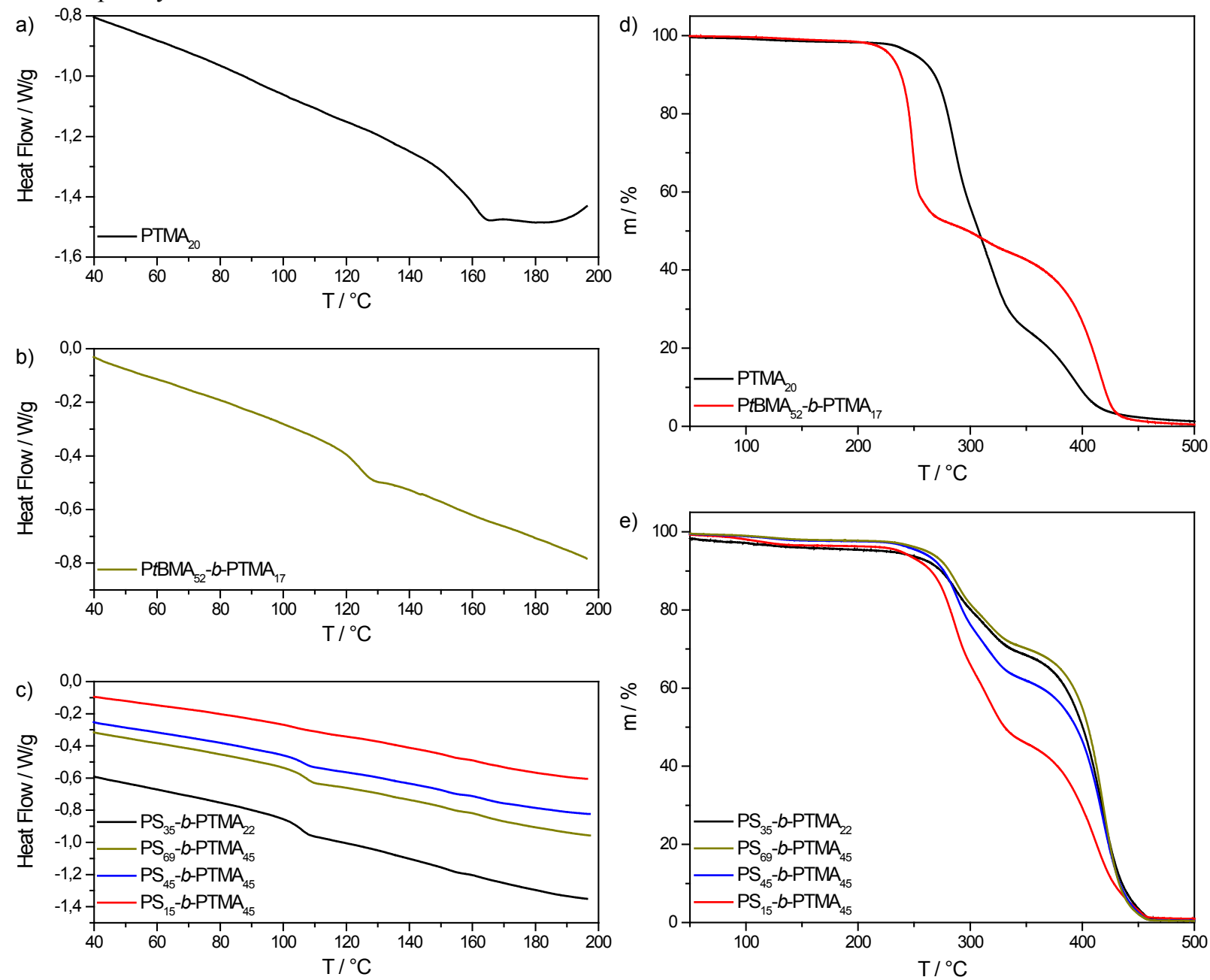

Figure SI-4: a-c) DSC curves of a) $\mathrm{PTMA}_{20}$, b) $\mathrm{P} \mathrm{BMA}_{52}-b-\mathrm{PTMA}_{17}$, c) $\mathrm{PS}_{35}-b-\mathrm{PTMA}_{22}$ (black), $\mathrm{PS}_{69}-b-\mathrm{PTMA}_{45}$ (green), $\mathrm{PS}_{45}-b$-PTMA 45 (blue), $\mathrm{PS}_{15}-b-\mathrm{PTMA}_{45}$ (red). d,e) TGA curves of d) $\mathrm{PTMA}_{20}$ (black), $\mathrm{P}_{t} \mathrm{BMA}_{52}-b-\mathrm{PTMA}_{17}$ (red), e) $\mathrm{PS}_{35}-b-\mathrm{PTMA}_{22}$ (black), $\mathrm{PS}_{69}-b-\mathrm{PTMA}_{45}$ (green), $\mathrm{PS}_{45}-b$ - $\mathrm{PTMA}_{45}$ (blue), $\mathrm{PS}_{15}-b$ - $\mathrm{PTMA}_{45}$ (red). 

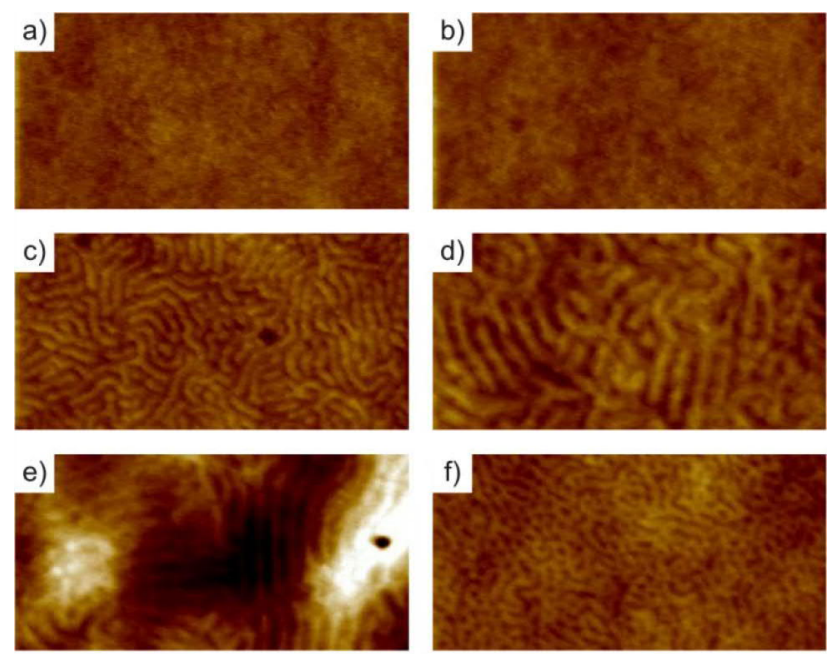

$250 \mathrm{~nm}$

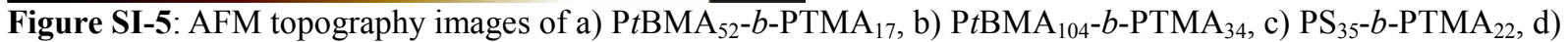
$\mathrm{PS}_{69}-b-\mathrm{PTMA}_{45}$, e) $\mathrm{PS}_{45}-b$-PTMA 45, f) $\mathrm{PS}_{15}-b-\mathrm{PTMA}_{45}$ after spin-coating from solutions in chloroform. The color coding bar $(\Delta \mathrm{z}=7.5 \mathrm{~nm})$ and scale bar correspond to all images.
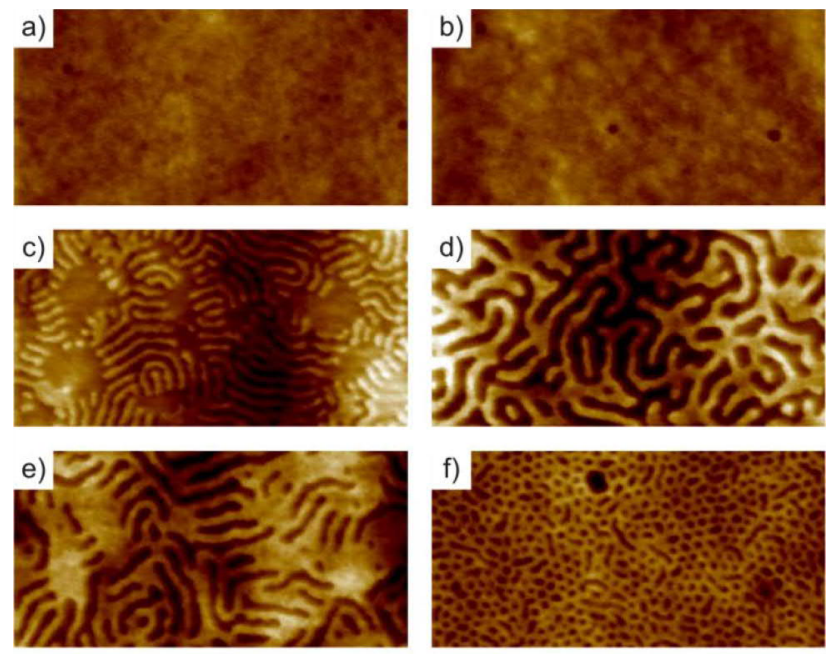

$250 \mathrm{~nm}$

Figure SI-6: AFM topography images of a) $\mathrm{P} t \mathrm{BMA}_{52}-b-\mathrm{PTMA}_{17}$, b) $\mathrm{P} t \mathrm{BMA}_{104}-b$-PTMA 34 , c) $\mathrm{PS}_{35}-b$-PTMA 22 , d) $\mathrm{PS}_{69}-b$-PTMA 45, e) $\mathrm{PS}_{45}$ - $b$-PTMA $45, \mathrm{f}$ ) $\mathrm{PS}_{15}-b$-PTMA 45 after spin-coating from solutions in chloroform and subsequent thermal annealing at $200{ }^{\circ} \mathrm{C}$ for $20 \mathrm{~min}$. The color coding bar $(\Delta \mathrm{z}=10 \mathrm{~nm})$ and scale bar correspond to all images. 

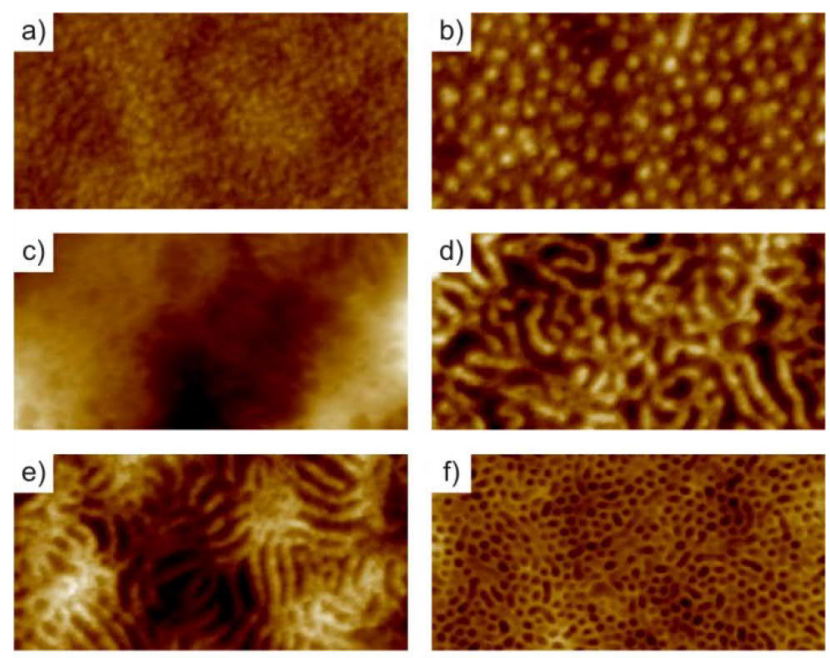

$250 \mathrm{~nm}$

Figure SI-7: AFM topography images of a) $\mathrm{P} \mathrm{BMA}_{52}-b-\mathrm{PTMA}_{17}$, b) PtBMA $104-b-\mathrm{PTMA}_{34}$, c) $\mathrm{PS}_{35}-b-\mathrm{PTMA}_{22}$, d) $\mathrm{PS}_{69}-b$-PTMA 45, e) $\mathrm{PS}_{45}-b$-PTMA $\left.45, \mathrm{f}\right) \mathrm{PS}_{15}-b$-PTMA 45 after spin-coating from solutions in chloroform and subsequent thermal annealing at $200{ }^{\circ} \mathrm{C}$ for $150 \mathrm{~min}$. The color coding bar $(\Delta \mathrm{z}=10 \mathrm{~nm}$, except c) $\Delta \mathrm{z}=20 \mathrm{~nm})$ and scale bar correspond to all images.
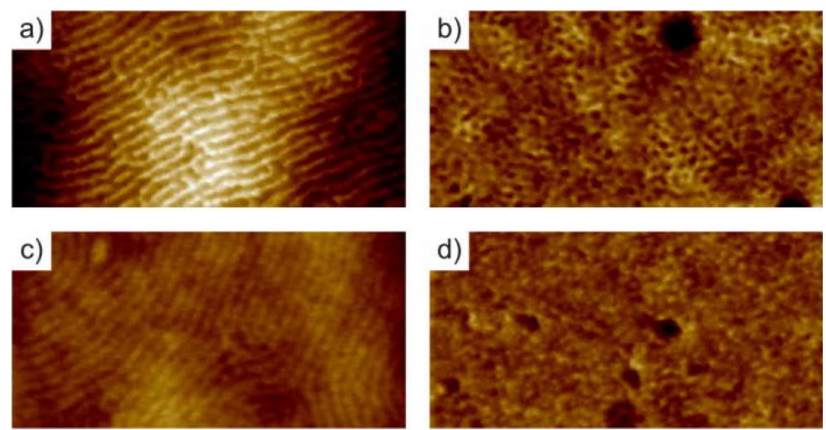

$250 \mathrm{~nm}$

Figure SI-8: AFM topography images of $\mathrm{PS}_{15}-b$-PTMA 45 films after spin-coating from chloroform (a,b) or toluene $(\mathrm{c}, \mathrm{d})$ and subsequent solvent vapor annealing in chloroform $(\mathrm{a}, \mathrm{c})$ or toluene vapor $(\mathrm{b}, \mathrm{d})$. The color coding bar $(\Delta \mathrm{z}=7.5 \mathrm{~nm})$ and scale bar correspond to all images.
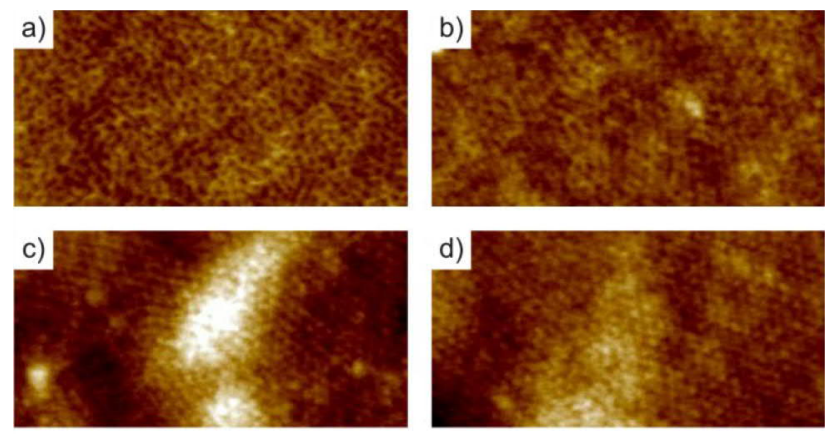

$250 \mathrm{~nm}$ 
Figure SI-9: AFM topography images of $\mathrm{PS}_{15}-b-\mathrm{PTMA}_{45}$ films after spin-coating from toluene and subsequent solvent vapor annealing in chloroform. Changing film thickness as a result of different concentration of the spincoating solution: a) $\sim 19 \mathrm{~nm}$; b) $\sim 43 \mathrm{~nm}$; c) $\sim 85 \mathrm{~nm}$; d) $\sim 253 \mathrm{~nm}$. The color coding bar $(\Delta z=5 \mathrm{~nm})$ and scale bar correspond to all images.

\section{References}

(1) Guo, W.; Yin, Y.-X.; Xin, S.; Guo, Y.-G.; Wan, L.-J. Superior Radical Polymer Cathode Material with a Two-Electron Process Redox Reaction Promoted by Graphene. Energy Environ. Sci. 2012, 5, 5221-5225.

(2) Wang, Y.; Song, X.; Shao, S.; Zhong, H.; Lin, F. An Efficient, Soluble, and Recyclable Multiwalled Carbon Nanotubes-Supported TEMPO for Oxidation of Alcohols. RSC Adv. 2012, 2, 7693-7698.

(3) Olmos, D.; Martín, E. V.; González-Benito, J. New Molecular-Scale Information on Polystyrene Dynamics in PS and PS-BaTiO3 Composites from FTIR Spectroscopy. Phys. Chem. Chem. Phys. 2014, 16, 24339-24349. 